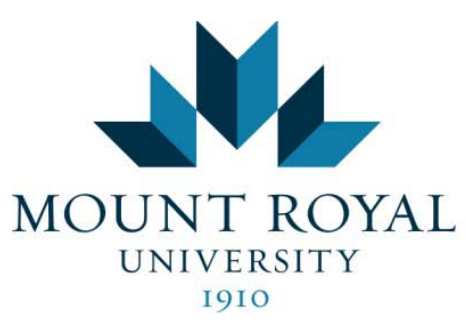

Department of

Education and Schooling

Mount Royal Undergraduate Education Review

Volume 1(2)

Fall 2014

\title{
Computer-based math curriculum reform: Incorporating digital technology into teaching mathematics
}

Nouralhuda Ismail, Mount Royal University

Link to Digital Story

\begin{abstract}
The issue in today's education is that teachers may be engaged in the role of teaching but not necessarily facilitating the learning process. This study was created to explore tools that will encourage and maximize student learning in mathematics. It highlights the advantages and possible disadvantages of incorporating digital technology into mathematics. Students tend to lose focus in the subject being taught due to a lack of interest. This is why curriculum reform is needed, in order to awaken and develop powers of creativity in teaching. I gathered an assortment of information through online surveys, interviews and field experience. My findings showed that positive math learning experiences were created through engaging students in math activities with the use of digital technology. The development of digital technology in curriculums such as math may just be the road to a successful curriculum reform. One that encourages and engages student curiosity, individuality and their creativity.
\end{abstract}




\section{Introduction}

Many students view math as a relatively dry and tedious subject. Students lose interest quickly when it is being taught in a traditional and dull manner. This has encouraged me to look into different teaching strategies in mathematics that will engage students in learning. Technology plays a significant role in society today, and it becomes very difficult to keep to traditional pedagogies when students are advancing in technology use and knowledge. My research questions were revolved around the effects of reform-based technology on student learning and classroom practices, specifically in mathematics. And whether the integration of such technology improves the student's academic achievement and understanding of mathematics. The research has allowed me to collect information relevant to mathematics and the task to transfer the subject to the digital world. I have explored a wide-range of ideas on how and what math concepts can be learned in the digital environment. Throughout my teaching practicum, I have rarely witnessed teachers integrating the use of technology in mathematics. This research will help me in my future teaching practices as I pursue my teaching career. Furthermore, it will provide other teachers and potential teachers with possible resources they could use to move student learning forward.

\section{Background}

It's important to build on prior research related to the use of digital technology in mathematics. Many studies have been conducted in order to understand the effectiveness and advantages as well as challenges of using digital technology to teach mathematics. Justin Burris conducted a study comparing how third graders learn place-value concepts through an integrated technology lesson. Students were better able to understand difficult place-value concepts through the available virtual tools that allowed them to break apart and reorganize quantities in order to construct multiple nonstandard forms (Justin, 2013). The study compared a normal math lesson to a technology 
integrated math lesson and whether the use of technology influenced their achievement. Burris mentioned the importance of not only integrating technology into math lessons but also knowing how students will interact with and think mathematically when using the technology.

An exploratory study discussed in the Journal of Undergraduate Mathematics Preparation of School Teachers examined student teachers' view in implementing technology in the math curriculum. The study explored different software programs that may be implemented in math lessons to help deliver challenging math concepts. The study discusses the importance of students' reaction to implementing such technology. Some students found it frustrating to understand the new programs and this distracted them from learning the actual math (Grundmeier \& Habre, 2007). The research discusses the importance for teachers to break down lesson plans. The first lesson plan should be mainly focused on using technology as a computational tool. The lesson plans to follow can then teach students how to use specific software programs to visualize, investigate and analyze mathematical concepts. The study articulates the importance of defining the role of the teacher when it comes to incorporating technology to teach mathematics. It illustrates the concept of adapting school curricula to include activities that utilize technology to teach mathematics and how this promotes a positive role in student learning and creativity.

Cheung and Slavin (2011) conducted an experimental study in the Educational Research Review Journal about the effectiveness of educational technology applications for enhancing mathematics achievement in K-12 classrooms. They evaluated a wide-range of educational technology including computers, multimedia, interactive whiteboards, and other technology, used to improve mathematical achievement. The study mentions that although there is an increasingly popular use of new educational technologies such as the interactive whiteboard system there is still little experimental research in this area and no qualifying studies to determine the significant 
difference in student achievement (Cheung \& Slavin, 2011). The researchers conclude by stating that new and better tools are needed to harness the power of technology to enhance the learning and student achievement in mathematics.

A couple of videos also discuss the need to change the way math is being taught and suggests embodying a more digital approach to teaching and learning mathematics. Dan Meyer, a Ph.D. Candidate at Stanford University explains the importance of student engagement on a TedTalks show. He believes in the use of classroom-tested math exercises that prompt students to stop and think as opposed to solve problems thoughtlessly. He has a great sense of what he wants to accomplish and what needs to be changed and integrated into the curriculum to achieve these goals. Similarly, Elly Schofield also discusses her frustration on a TedTalks show with math being too focused on accuracy and computation. Elly believes that Mathematics is not about computation but rather about problem solving. She puts forth her idea of what more effective math curriculum might look like in the future.

Although the topics of math and technology have been explored, there still is not a concise method of implementing technology into teaching mathematics. Most researchers agree with creating a link to real life applications in mathematics but have not discussed its relation to the use of digital technology. Teachers need to have a full understanding of how to use technologies properly; however, they are not being taught these correct teaching methodologies in university. Kirkwood (2000) states, "Even in those universities that have technology education programs, most undergraduates do not take a required course in technology concepts” (n.p). Mathematics is an important academic discipline that needs to be taught to students' in a way where they are engaged in the topic and understand its relation to future success in life. 


\section{Research Context}

Data had been gathered from a wide-range of people including instructors, students, colleagues and parents (a total of thirty-one participants). As well as a collection of different sources from journal articles, books, interviews, and surveys. Interviews have been conducted with professors, teachers and parents in order to obtain additional information about their knowledge on incorporating technology into mathematics. Most participants were selected based on their experience in implementing technology in their teaching. No names were mentioned in the research unless participants had given their permission. All participants were aware of the research being conducted and permission was requested prior to data collection.

\section{Methods of Investigation}

The methods of investigation that was used to gather data for this research project included online surveys using yes/no, short and long answer questions, conducting interviews, peer discussions, scholarly sources and journal notes. It was important to include various participants such as professors, instructors, university students’ and parents perspectives and experiences in my research topic. Furthermore, including observations of instructors with experience in using digital technology in teaching mathematics was crucial in understanding this topic. I chose to conduct an online survey (Appendix A) first to discover the demographics of the people who were participating in my research. The purpose of this survey was to identify the value of incorporating technology into mathematics. The survey consisted a mixture of scale and open-ended questions. I then chose to interview professors, instructors and parents to further clarify and understand their views on the research topic. Observing classrooms that incorporated digital technology in their math lesson allowed me to view real situations where students were participating in various math activities that was directly related to my research. 
I organized the data using Google Drive and the Google Forms survey program. My

interviews were recorded on the iPhone Voice Memo app and the classroom observations were

written in a journal. I analyzed the data by comparing perspectives and common themes. Being able to split the responses into categories made it easier to see where the common perspectives including benefits and challenges regarding mathematics and technology were more popular. Furthermore, I used word clouds, charts, and graphs to compare the data I had collected. Google Drive made it easy to manage and access the data information at all times.

\section{Findings}

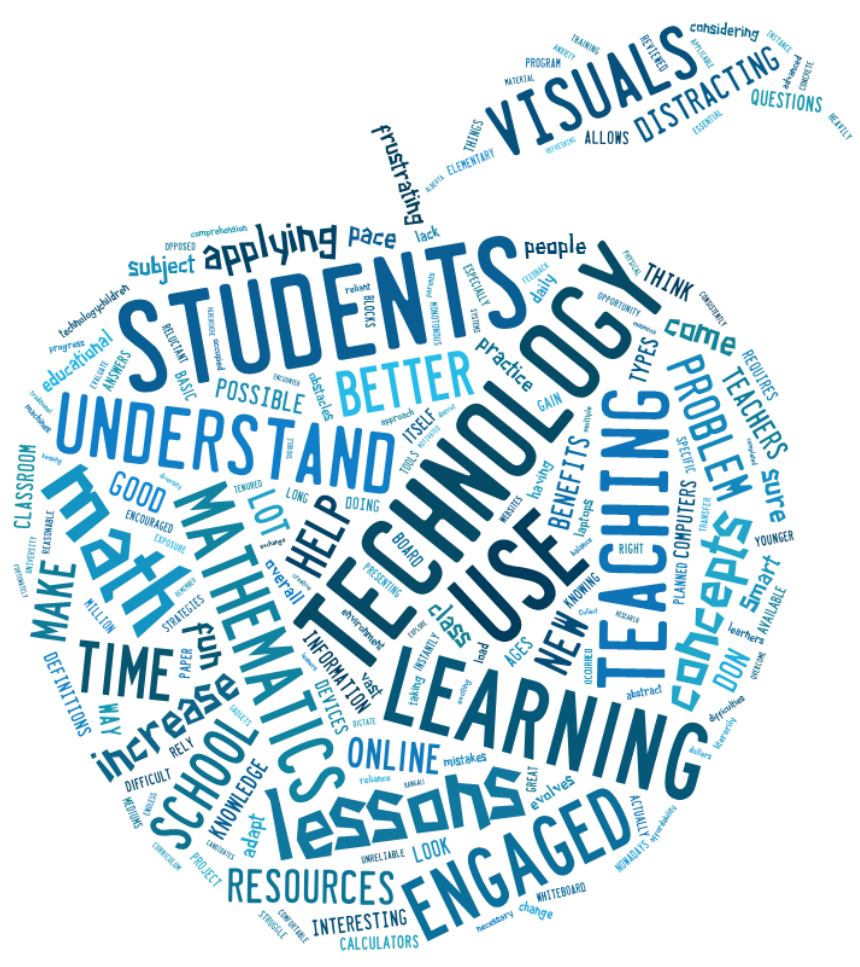

Figure 1. Summary of collected survey response

After collecting the results and survey response (Figure 1), I was able to start analyzing my findings and the significance they offered to this research. I conducted further interviews and classroom observation after looking at the survey data and identifying areas that needed to be further 
looked at. Thirty-one people took part in my online survey; a total of ten instructors, fifteen students, and six others (Figure 2).

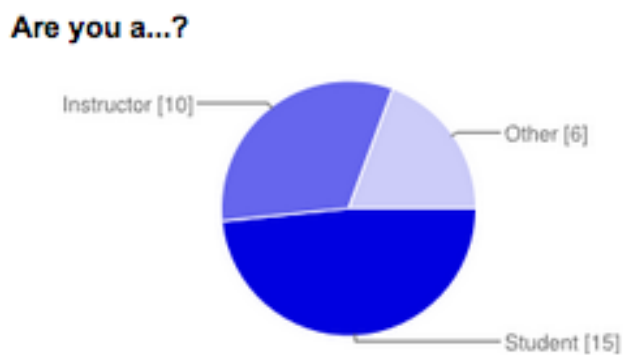

$\begin{array}{lrr}\text { Student } & 15 & 48 \% \\ \text { Instructor } & 10 & 32 \% \\ \text { Other } & 6 & 19 \%\end{array}$

Figure 2. Demographics of survey participants

Not all classrooms used digital technologies. In the online survey I created, when participants were asked if they had experienced or taught an integrated math lesson in the classroom the majority gave traditional tools opposed to digital technologies. These included tools such as: chalkboards, textbooks, math games, and whiteboards. The only digital technologies mentioned were SMART Boards, projectors and calculators (Figure 3).

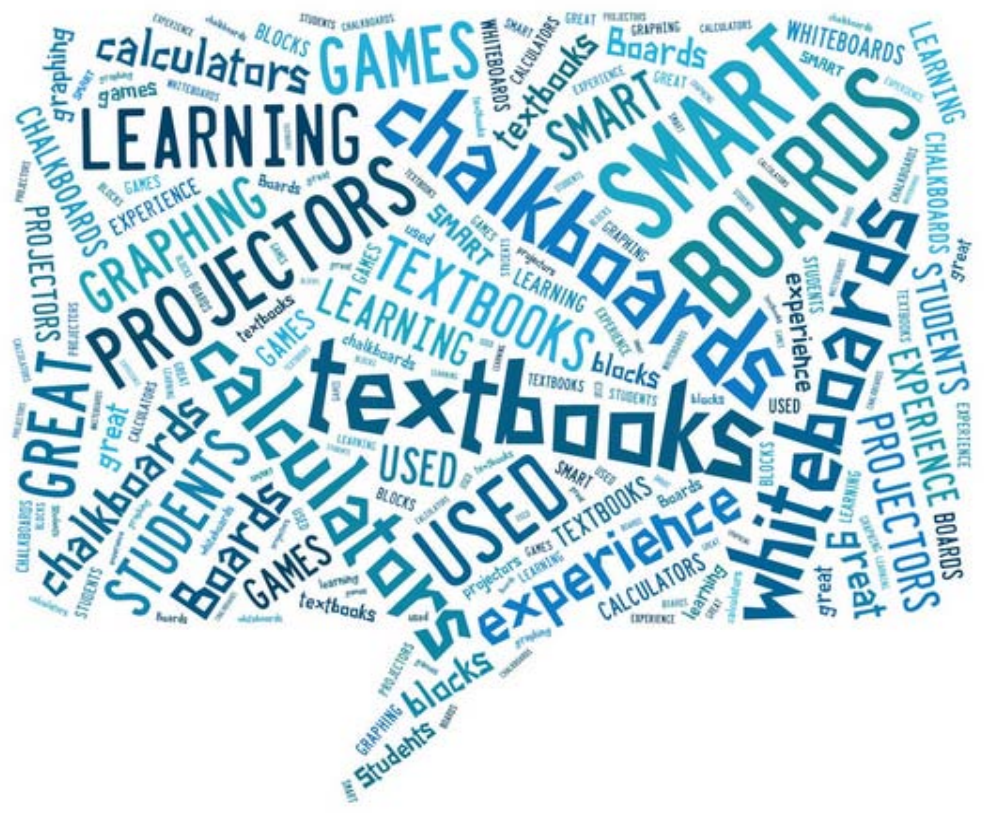

Figure 3. Common tools used in the mathematics classroom 
It is clear that digital technology is not as commonly used in mathematics. When participants were asked how often they had seen technology being integrated into mathematics, only a few responded positively (Figure 4).

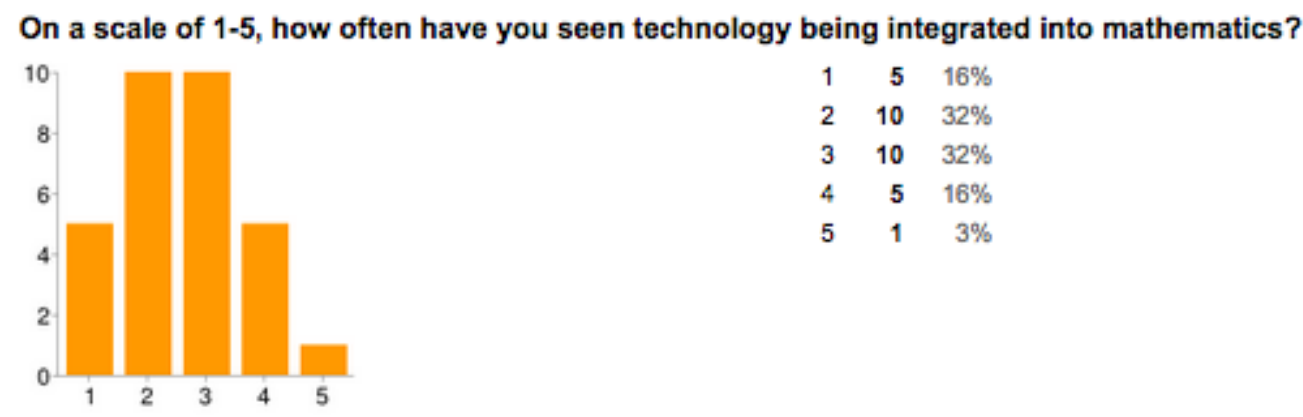

Figure 4. Participants who have seen technology integrated into mathematics

Only about six percent of participants had experienced or taught a technology integrated math lesson (Figure 5). The lessons that were mentioned included perimeter, area and shapes. The digital technology that was used to teach those lessons involved videos about shapes on the SMART Board and perimeter/area illustrations on the projector. Instructors commented that the technology used did not display much positive learning experience as most students were not interested in the video or illustrations.

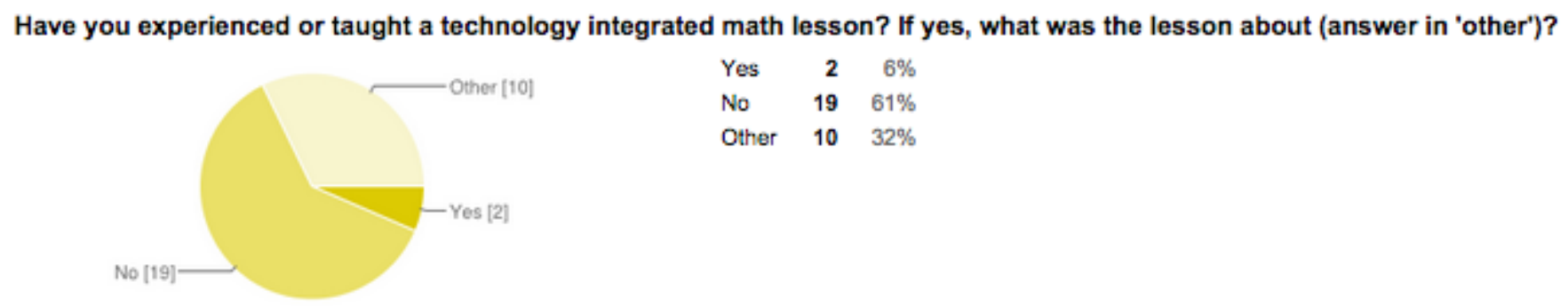

Figure 5. Percentage of participants experienced or taught a technology integrated math lesson It was crucial for me to know whether there would be a spark of interest in learning or teaching mathematics if technology was apart of the equation. About eighty percent of the 
respondents said they would be quite interested (Figure 6). Most teachers are interested in teaching mathematics with the use of technology and students like so with learning.

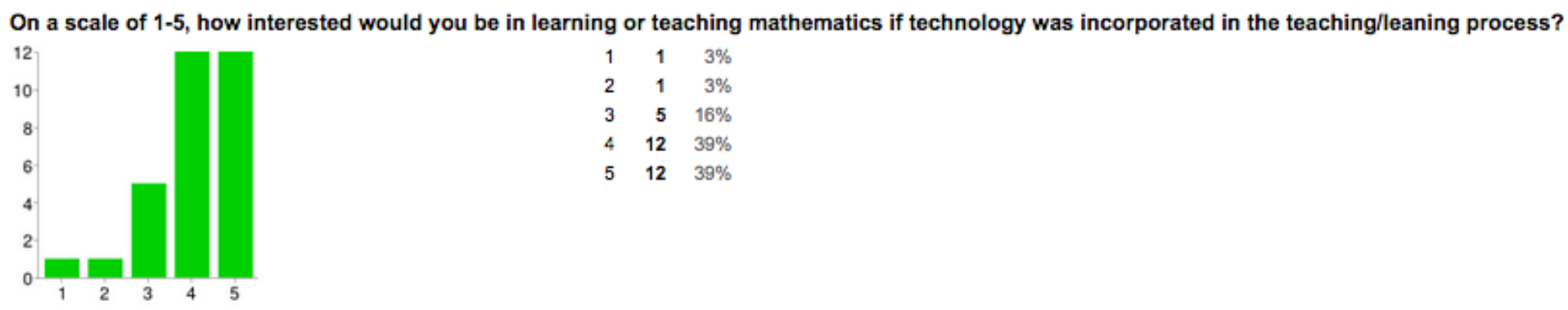

Figure 6. Participants interested in teaching/learning mathematics with the use of technology

In my online survey I had a few open-ended questions asking about what possible benefits or challenges may occur with integrating the use of technology into mathematics (Appendix A). There were many repeating themes which I organized into a table of the most common responses (Table 1).

Table 1

Possible benefits and challenges of incorporating technology into mathematics

\begin{tabular}{|c|c|c|c|}
\hline \multicolumn{2}{|r|}{ Benefits } & \multicolumn{2}{|r|}{ Challenges } \\
\hline 1. & Engages students to learn more and go & 1. & Too much reliance and lack of basic skills \\
\hline & through the lessons at their own pace. & 2. & Not much learning achieved if technology \\
\hline 2. & Creates a more interactive environment & & is not of good value \\
\hline 3. & Allows student to visualize mathematical & 3. & Students may be distracted \\
\hline & concepts & 4. & Depend on technology and lose basic \\
\hline 4. & Gives students the opportunity to ask & & math skills/reasoning \\
\hline & questions anonymously to better & 5. & Affordability of technology and training \\
\hline & understand a topic & & teachers \\
\hline 5. & Different ways of presenting information & 6. & Difficult to assess students learning \\
\hline
\end{tabular}




\begin{tabular}{|c|c|c|c|}
\hline & thus accommodating for different learning & & Takes too much time \\
\hline & styles & 8. & Technology can become boring and \\
\hline 6. & Fun learning & & monotonous if not planned properly \\
\hline 7. & $\begin{array}{l}\text { Help students focus, may offer a better } \\
\text { understanding and recalling math }\end{array}$ & 9. & $\begin{array}{l}\text { There are perhaps some concepts in math } \\
\text { that can't be learned as effectively through }\end{array}$ \\
\hline & concepts & & technology \\
\hline 8. & Increase math interest & 10. & May be difficult or frustrating for students \\
\hline 9. & $\begin{array}{l}\text { Use of technology can enable students to } \\
\text { share their work }\end{array}$ & 11. & $\begin{array}{l}\text { Parents or guardians may be against the } \\
\text { idea }\end{array}$ \\
\hline 10. & $\begin{array}{l}\text { Possibly increase overall student } \\
\text { achievement }\end{array}$ & 12. & May slow down lessons \\
\hline 11. & $\begin{array}{l}\text { Increase opportunity to practice and apply } \\
\text { mathematics }\end{array}$ & & \\
\hline 12. & $\begin{array}{l}\text { Students gain the knowledge, confidence, } \\
\text { and math skills that they will use } \\
\text { throughout their learning experience }\end{array}$ & & \\
\hline
\end{tabular}

By analyzing my open ended survey questions, I identified the following concerns about the use of digital technologies in the mathematics discipline:

1. Lack of basic math skills development

2. The issues of affordability

3. Finding the appropriate technology

4. Possibility of student frustration and/or distraction 
In regards to the first concern, one teacher commented, "I have my doubts with the use of technological tools. Knowing basic math skills is crucial ... I think there is so much importance in the good old paper and pencil method” (Teacher Participant 1). This sentiment was echoed by a teacher participant who stated "I feel like technology can compliment these strategies, but not replace them. Mathletics is a good example... [It] has activities that build on the basics to strengthen their understanding but cannot build the foundation alone ” (Teacher Participant 2).

A teacher participant stated that "Sometimes struggling students do not respond appropriately to technology" and that "digital technology may help, but if a student is struggling they often need specific one on one guidance from a person” (Teacher Participant 3).

A teacher at a private school stated issues with affordability, "Sure it's great to incorporate technology into classrooms and the Connect Charter School is a great model of this, but there is a big issue with affordability and especially for private schools” (Teacher Participant 4)

With regards to the fourth concern, one professor participant commented that "[Digital Technologies are] excellent for visualizing, engaging students and for independent students to try to work through some concepts on their own. [However;] the main disadvantages is that it is not as personal and may be frustrating for students especially in the lower grades ” (Professor Participant 1).

Finally, a professor participant stated that "Applying technology to mathematics seems like a great idea, but when it comes to practicality, it usually isn’t . The most effective way to get students to excel in math is to provide a safe environment where they don't have to worry about their grades. You have to encourage the students and be supportive... perhaps one-on-one tutoring until they realize that they really do have the ability to learn math concepts” (Professor Participant 2). 


\section{Conclusions and Recommendations}

This research study has had a major impact on my view in incorporating technology into academic disciplines as a future teacher. It has demonstrated to me the importance of engaging students through the use of digital technology. With that being said, it is crucial that students are learning the basic mathematical skills before moving on to bigger concepts in mathematics involving digital tools. Teachers need to create an environment where students are engaged in their learning. Meyer (2010) discussed a few of the main problems in math classes including, "lack of initiative, students don't self start, lack of perseverance, lack of retention and eagerness for formula to apply”.

I have had the opportunity to attend the Innovate West Annual Conference 2014 hosted by the Connect Charter School. It was a conference that united educators and pushed for new ideas in the education system. The Connect Charter School is keen about enhancing learning and teaching through the effective use of technology. This relates to my own philosophy of teaching because I believe that one reason for the lack of student engagement and motivation is due to a learning environment lacking in the opportunity for students to integrate technology. Teachers need to move beyond the blackboard and whiteboard teaching methods. Instead we need to find ways to bring out the best of a student's potential and that is through current technology devices that they are engaged in. The Connect Charter School implements the use of technology by having students use current technology devices such as laptops, iPads, software programs and other forms of advanced technology in their classes.

An example of students using technology in math class is illustrated in Figure 7. The students were asked to create a structure or shape with fraction segments. Then required to take a picture of their shape and identify what fraction parts they used to complete their task (Figure 8). As an extension, students were asked to add all their fraction segments and write the total sum. It was 
amazing to see how engaged students were in the learning process. Integrating technology in their fraction unit allowed them to visualize fraction concepts. The classrooms at the Connect Charter School are structured so that the desks are arranged into clusters for students to collaborate with each other and discuss their ideas as a group. This constructivist learning approach incorporated with the use of digital technology has the potential to move student learning forward.

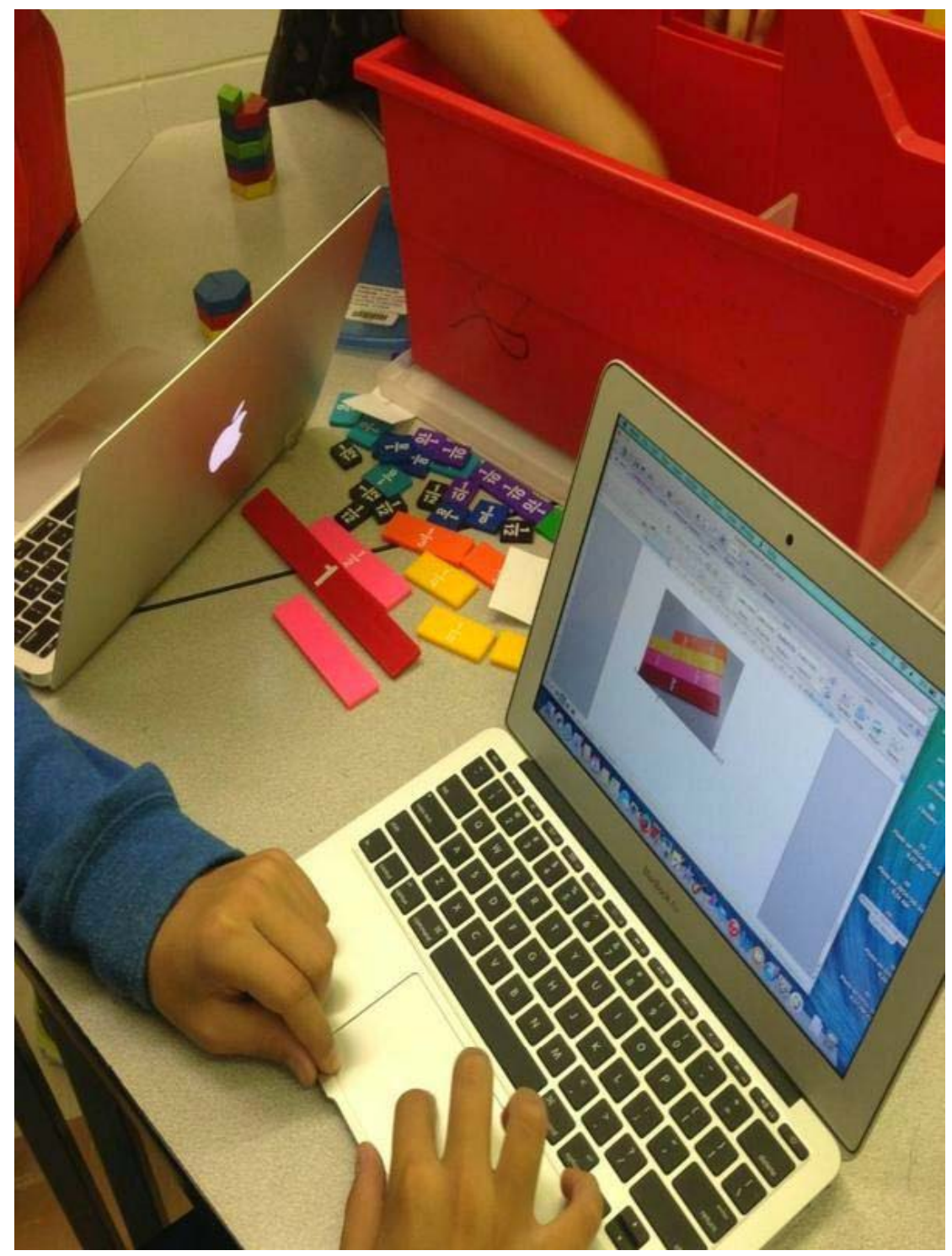

Figure 7. Fraction assignment using digital technology 


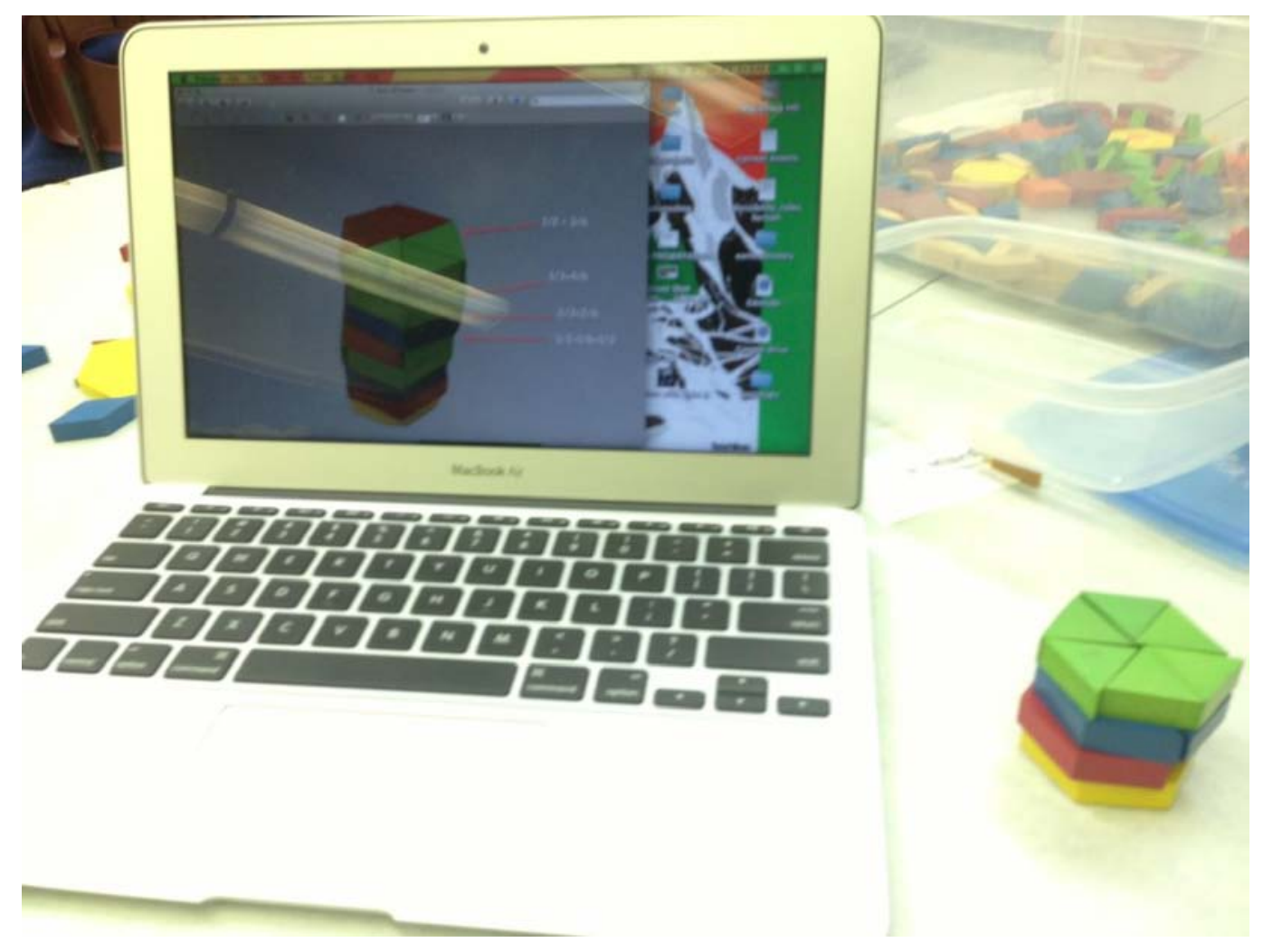

Figure 8. Identifying fraction segments within the built structure

I had read a few articles about technology in schools and although the availability of instructional technology alone does not guarantee improved comprehension of content (Filer, 2010), yet schools without technology perform at a lower level compared to schools that have and use it (Solhaug, 2009). In the article Teaching with Technology, the authors state that, "The technology gap between schools and the rest of the world is real, and it is growing...If we plan carefully, if we bring teachers along with us and implement new technology wisely together with other needed reforms, learning could be dramatically better” (McCormack \& Ross, 2010, p. 45). Teachers need to be taught how to use technology in university education courses and professional development workshops to understand how to integrate it most effectively. 
Mathletics for instance is a web-based learning program that allows students to work on math problems and activities in an online interactive environment. They can compete with students internationally in this online learning environment. Mathletics covers the math curriculum as well as enhances student achievement in mathematics. A recent research titled, Mathletics: Does it enhance achievement in mathematics, was conducted at Deakin University. The research concludes that Mathletics does enhance student achievement in mathematics through the engagement in, and enjoyment of solving interactive math problems (Doig, 2012). Thus, teachers need to integrate the use technology as an assistive tool much like Mathletics to increase student engagement and achievement.

This research made me realize the true potential we have to improve classroom structures and ultimately the education system. As teachers, it is crucial to research and learn about the different ways we can successfully integrate technology to engage students. I believe that teachers are now no longer responsible for teaching, but responsible for facilitating learning, that's the real shift in education.

\section{References}

Burris, J. T. (2013). Third graders' mathematical thinking of place value through the use of concrete and virtual manipulatives. Teaching children mathematics, 20(4), 228.

Cheung, A., \& Slavin, R. (2011). The effectiveness of educational technology applications for enhancing mathematics achievement in K-12 classrooms: A meta-analysis. Educational Research Review, 88-113. Retrieved October 27, 2014, from http://www.bestevidence.org/word/tech_math_sep_09_2011.pdf

Doig, B. (2012). Mathletics: Does it enhance achievement in mathematics. Association of Independent Schools of Victoria. 
Filer, D. (2010). Everyone’s answering: Using technology to increase classroom participation. Nursing Education Perspectives, 31(4), 247-250. Retrieved from http://web.b.ebscohost.com.ezproxy.lib.ucalgary.ca/ehost/detail?vid=10\&sid=f6113147-3e134a90-b382053a8210cbec\%40sessionmgr113\&hid=118\&bdata=JnNpdGU9ZWhvc3QtbGl2ZQ\%3d\%3d\# $\underline{\mathrm{db}=e r i c \& A N=E D 541343}$

Grundmeier, T., \& Habre, S. (2007). Prospective Mathematics Teachers' Views on the Role of Technology in Mathematics Education. Issues in the Undergraduate Mathematics Preparation of School Teachers. Retrieved from: http://files.eric.ed.gov/fulltext/EJ835509.pdf

Kirkwood, J. J. (2000). The status of technology education in elementary schools. Journal of Industrial Teacher Education, 37(3). Retrieved from http://scholar.lib.vt.edu/ejournals/JITE/v37n3/kirkwood.html

Liu, Y. (2013). A Comparative Study of Integrating Multimedia into the Third Grade Math Curriculum to Improve Math Learning. Journal of Computers in Mathematics and Science Teaching, 32(3), 321-336. Chesapeake, VA: AACE.

McCormack, S., \& Ross, D. (2010). Teaching with technology. The Science Teacher, 77(7), 40- 45. Retrieved from http://learningcenter.nsta.org/browse_journals.aspx?journal=tst

Meyer, D. (2010, May 13). Dan Meyer: Math class needs a makeover [Video file]. Retrieved from https://www.youtube.com/watch?v=NWUFjb8w9Ps

Schofield, E. (2012, Nov 6). A Passion for Math: Elly Schofield [Video file]. Retrieved from: https://www.youtube.com/watch?v=sBPKoTr-XnQ 
Solhaug, T. (2009). Two configurations for accessing classroom computers: Differential impact on students' critical reflections and their empowerment. Journal of Computer Assisted Learning, 25(1), 411-422. Retrieved from

http://web.b.ebscohost.com.ezproxy.lib.ucalgary.ca/ehost/detail?vid=13\&sid=f6113147-3e134a90-b382-

053a8210cbec\%40sessionmgr113\&hid=118\&bdata=JnNpdGU9ZWhvc3QtbGl2ZQ\%3d\%3d\#

$\underline{\mathrm{db}=\mathrm{eric} \& A N=\mathrm{EJ} 853310}$ 


\section{Appendix A: Online Survey Questions}

Important Note: I have completed the Canadian Ethical Conduct for Research Involving Humans Course on Research Ethics. The purpose of this survey was to gather participant responses to determine the value of integrating technology into mathematics. Participation in the survey was completely voluntary and permission was requested prior to conducting interviews and data collection.

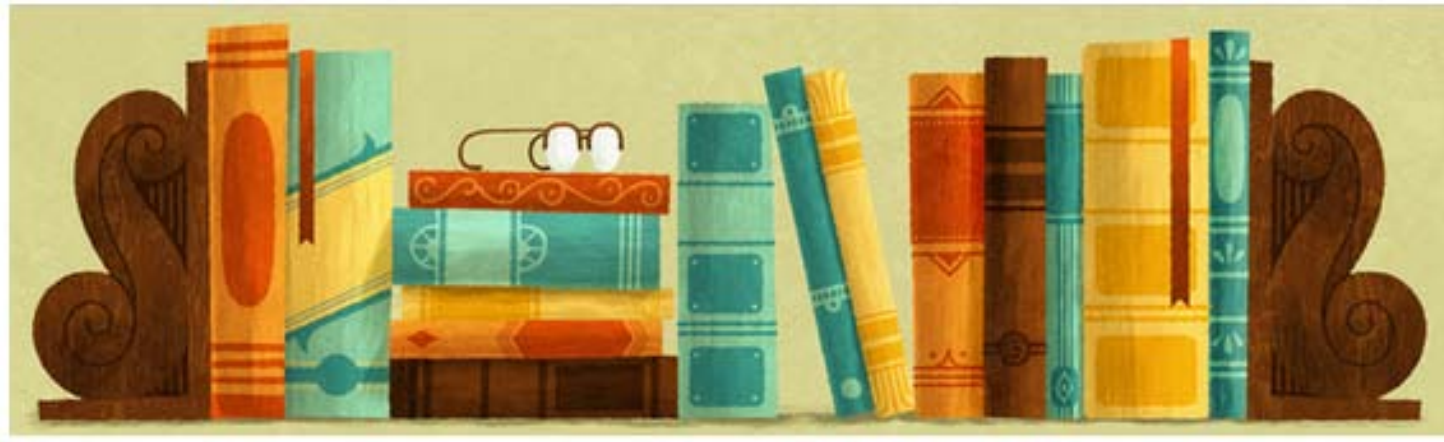

\section{Integrating Jechnology in the Mathematics Curriculum}

For some students learning math can be quite challenging. This survey will collect information relevant to mathematics and the task to transfer the subject to a digital world. It will allow me to explore ideas of how (and what) math concepts can be learned in an online environment.

* Required
Are you a...?*
Student
Instructor
Other

On a scale of $1-5$, how often have you seen technology being integrated into mathematics? *

$\begin{array}{lllll}1 & 2 & 3 & 4 & 5\end{array}$

Never $\odot \circ \bigcirc$ Always 
Has someone you know (children, siblings, friends etc) mentioned an interactive learning lesson they have experienced in mathematics? *

Yes

No

Other:

Have you experienced or taught a technology integrated math lesson? If yes, what was the lesson about (answer in 'other')? *

Yes

No

Other:

On a scale of 1-5, how interested would you be in learning or teaching mathematics if technology was incorporated in the teaching/leaning process? *

$1 \quad 2 \quad 3 \quad 4 \quad 5$

Not interested $\bigcirc \circ \bigcirc \bigcirc \bigcirc$ Very interested

What are possible benefits you may expect to find with integrating technology into mathematics? *

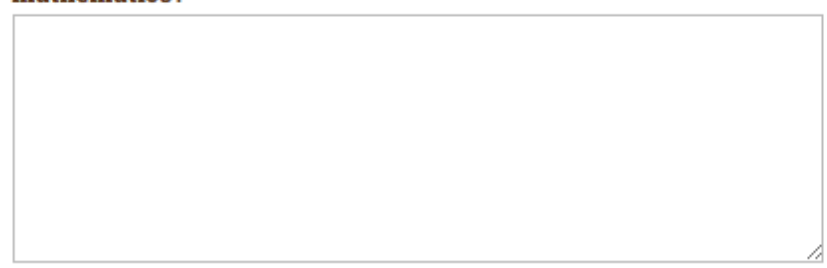

What challenges or obstacles do you expect will occur with integrating technology into mathematics? *

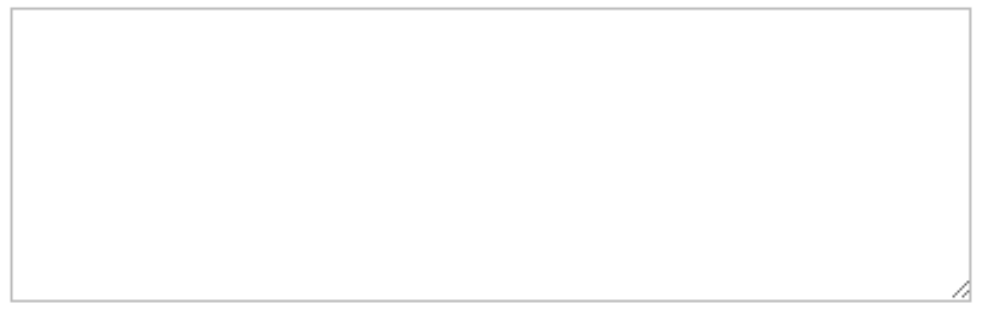

What advice/comments would you give me as a future teacher in terms of integrating technology into the mathematics curriculum? *

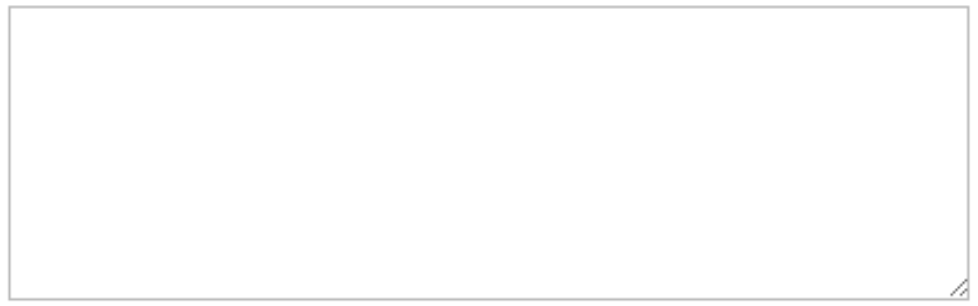

